\title{
The possibility of extending work time of tribocouple welding improved stainless steel with improved carbon steel
}

\author{
Vlatko Marušić ${ }^{1}$ Predrag Dašićn ${ }^{2}$ Ivan Opačak $k^{*}$ \\ ${ }^{1}$ Mechanical Engineering Faculty in Slavonski Brod, Trg Ivane Brlic-Mazuranic 2, Croatia \\ ${ }^{2}$ SaTCIP Publisher LTD., Tržni centar Pijaca 106a, Serbia
}

\begin{abstract}
In the conditions of tribo-corrosion wear, extending of life time of parts can be achieved by using stainless steel, which is hardened to sufficiently high hardness. In the tribopair bolt/shell/slice of the bucket elevator transporter conveyor machine, the previously improved martensitic stainless steel for bolts is hardened at $\approx 45 \mathrm{HRC}$ and welded with the improved high yield carbon steel for bolts. As the additional material, an electrode based on Cr-Ni-Mo (18/8/6) is used. The structure and hardness of welded samples are tested. On the tensile tester, resistance of the welded joint is tested with a simulated experiment. Dimensional control of wear of elements of tribopair was performed after six months in service. The analysis of test results showed that with regulated additional material and by applying the recommended welding parameters, the properties of the weld, which provide the necessary reliability of the joint in the conditions of tensile load, can be achieved, with a significant increase in the wear resistance of bolt.
\end{abstract}

\section{Introduction}

In case of complex mechanisms wear is esspecially evident need for choosing proper type of materials and as well technological and construction parameters [1, 2]. In terms of tribo-corrosion wear basic elements of tribocouple material should be resistant to aggressive media, sufficiently high hardness with the satisfaction of the conditions of tribological compatibility [3]. For research of specifics that appear in tribo-corrosion wear is selected tribocouple in which damage of the elements is caused by corrosion due to abrasive and adhesion wear. A striking example of such wear is a tribosystem of bucket elevators for transporting of oil cake [4]. In order to determine the possibilities of extending the life to tribocorrosion exposed parts recording condition must be done. Then choose your own variant materials and procedures to protect against wear. At the laboratory samples perform metallographic examination and hardness measurements. Samples-parts install in the drive, and comparing them with the original parts of elevator monitor wear resistance under real conditions. Final control of metallographic examinations traces of wear and intensity of wear should provide insight into the possibility of extending the life of tribosystem elements.

\section{Wear of original parts of elevators}

Visual check of the original parts of elevators is performed: internal and external slices, internal and external link shoes, shell and bolt and buckets that are bolted on link shoes (every third segment of the chain).
According to the original documentation: breaking force of elevator chain is about $2500 \mathrm{~N}$ and declared service life of a chain is two years. Figure 1 shows the parts of the original elevator chain after about six months of work.
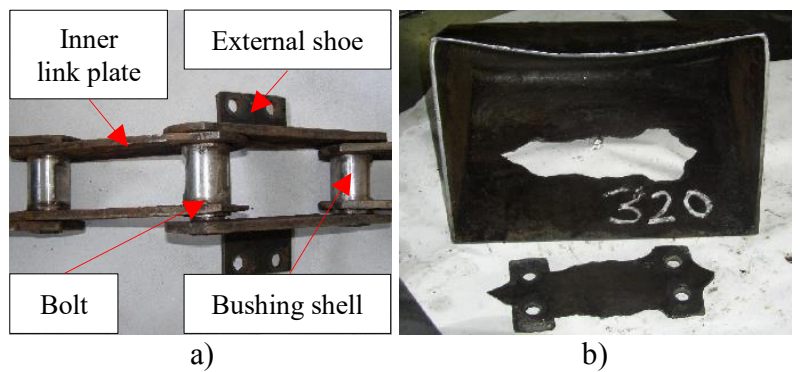

b)

Fig. 1. Appearance a damaged chain (a); buckets severed of link shoes (b).

Dimensional control measured: 1 . wear of a bolt is $\approx 3$ $\mathrm{mm}$, only the surface of bolt in contact with capsule is worn; 2 . only the surface of bolt in contact with capsule is worn; 3 . wear of a shell on the outside is $\approx 2,2 \mathrm{~mm}$ and on the inside to $\approx 1 \mathrm{~mm}$, with emergence of upsetting compund shell/slice and increasing the gap at about 0,8 $\mathrm{mm}$ by an upsetted compound. Chain pitch is $160 \mathrm{~mm}$. Wear of a tribocouple, which causes a change in chain pitch (slice, shell and bolt) is about $8 \mathrm{~mm}$, and there is 6,25 tribocouples on meter of a chain. Conclusion can be that the chain extension, as a result of wear parts, can reach more than $50 \mathrm{~mm}$ per meter, resulting in overall chain elongation of $1,600 \mathrm{~mm}$ in total length chain of 32 $\mathrm{m}$. Wear so big reflects to chain pitch, and this sometimes results in ripping buckets of link shoes.

\footnotetext{
*Corresponding author:iopacak@sfsb.hr
} 


\subsection{Laboratory tests on the damaged original parts of chain}

Chemical analysis showed that the slice and link shoes, are made of improved steel, C45E. The measured surface hardness of slices and link shoes, mean is about $210 \mathrm{HB}$. The thickness of these parts of the chain before the installation was $8 \mathrm{~mm}$. Dimensional control was found that the corrosion caused local reducing of thickness on max. 6,8 mm. Metallographic search were carried out on a sample taken from a damaged external slice, Figure 2. In slice is pressed bolt $\varnothing 30 \mathrm{~mm}$ which is additonally welded to the outer side on the slice.

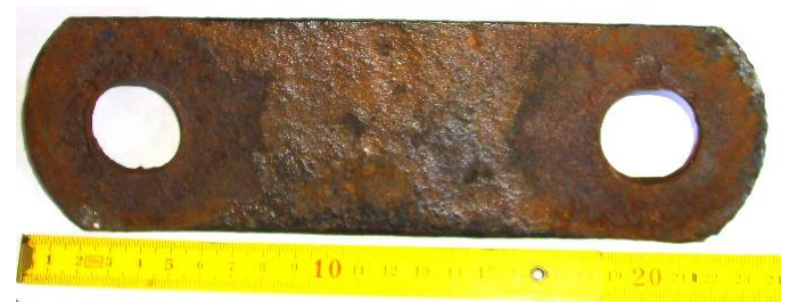

Fig. 2. Original damaged slice.

Chemical analysis showed that the bolts $(\varnothing 30 \times 83 \mathrm{~mm})$ and shells $(\varnothing 42 / \varnothing 30$ × $65 \mathrm{~mm})$ made of austenitic corrosion steel X5CrNiMo17-12-2 [5]. From damaged bolt $\varnothing 30 \mathrm{~mm}$, shown in Figure 3.a, sample was cutted and control of hardness is performed. The cross-section of the test sample of damaged bolt is shown on Figure 3.b.

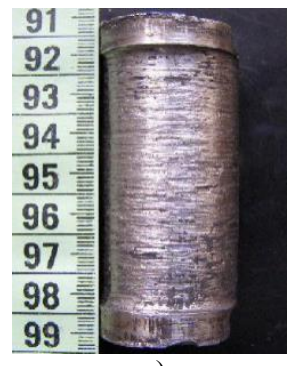

a)

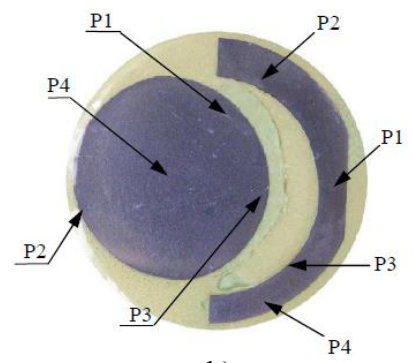

b)
Fig. 3. The appearance of the original bolts in place, ,worn place" (a); macro recording cross-sectional sample with marked positions of measuring the hardness of the bolt and the bushing shell (b).

Test of shell is carried out on spot of damaging in towing part with the bolt, Figure 4.a, and in the outer side in contact with the sprocket, Figure 4.b.

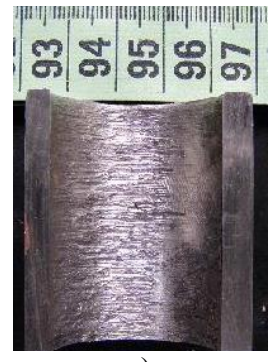

a)

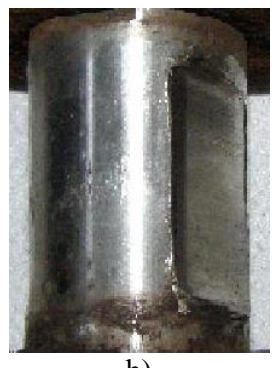

b)
Fig. 4. The appearance of the original bolt on spot ,worn place“ (a); macro recording of cross-sectional sample with marked positions of measuring the hardness of the bolt and shell (b).
At the macro recording of cross-section of damaged shells, positons of hardness HV1 measuring are marked, Figure 3.b. Hardness values measured HV1 from surface to core of sample taken from damaged bolt and shell are showed in Table 1.

Table 1. Result of hardness measurements HV1 on sample of damaged bolt and shell.

\begin{tabular}{|c|c|c|c|c|}
\hline \multirow{2}{*}{$\begin{array}{c}\text { Distance } \\
\text { from edge, } \\
\text { mm }\end{array}$} & \multicolumn{4}{|c|}{ Hardness, HV1 } \\
\cline { 2 - 5 } & $\begin{array}{c}\text { position } \\
\text { S1 }\end{array}$ & $\begin{array}{c}\text { position } \\
\text { S2 }\end{array}$ & $\begin{array}{c}\text { position } \\
\text { C1 }\end{array}$ & $\begin{array}{c}\text { position } \\
\text { C2 }\end{array}$ \\
\hline 0,1 & 294 & 269 & 269 & 348 \\
\hline 0,25 & 283 & 276 & 269 & 330 \\
\hline 0,5 & 239 & 269 & 251 & 357 \\
\hline 1 & 193 & 251 & 229 & 219 \\
\hline 1,5 & 182 & 234 & 214 & 189 \\
\hline 2 & 168 & 214 & 210 & 193 \\
\hline 3 & 171 & 182 & 205 & 185 \\
\hline
\end{tabular}

\section{The results of own variant materials}

Analyze of recording results of condition are: 1 . slices and link shoes are made from shell for improving, and the cause of their damage is corrosion due to the presence of fat acids in the cake; 2 . shells and bolts are made of austenitic stainless steel and were damaged by abrasion particles of crust, but also by adhesion in the area of mutual contact; 3 . because of a corrosion impact of agressive media on link plates and link shoes, damaging of their connecting spots with pressed bushing shells has been observed. A final result of all wear processes is increasing of a chain step and ,upon contact" of the sprocket. This could cause the appearance of inadmissible stress and appear of breakout of connect spots with bushing shell.

\subsection{The choice of own variant materials for wear resistance research}

Based on the results of the recording situation, conclusion was that the most critical element in tribosystem are bolt and shell. The dominant mechanism of wear is abrasion with particles of grind and adhesion in area of mutual contact, and shell contact with sprocket. Another critical spot is contact of shell and bolt with slice link shoes. For creating samples/bolts on which will be performed experiments are selected martensitic stainless steel in an improved condition X20Cr13 [5]. These bolts are then induction hardened. It was measured that the surface hardness of the bolt is in the range of $55 \div 57 \mathrm{HRC}$. Test bolts are welded to slice with MMA procedure. As additional material is used electrode based on $\mathrm{Cr}-\mathrm{Ni}-\mathrm{Mn}$ $(18 / 8 / 6)$, classified by EN 1600 [6]. Electrode diameter is $\varnothing 3,25 \mathrm{~mm}$, instesity of current is $I \approx 80 \mathrm{~A}$. Material of slice is C45E. Samples/bolts are incorporated in new original elevator chain at the beggining of processing sunflowers. 
In this chain shell are made from steel for cementation $16 \mathrm{MnCr} 5$. Effective layer depth of bushing shell was $\approx$ $0,8 \mathrm{~mm}$ from inside and outside. Measured surface hardnesses of shell are in range from 55 to $58 \mathrm{HRC}$.

\subsection{Test results of own variant samples/parts}

In order to verify welded compound bolt/slice were tested on the testing machine with static tensile tests. The load is added untill the termination of welded compound, and broken places served for metallographic examination and hardness control. The appearance of the welded compound slice/bolt after testing is showed on Figure 5.a. The cross-section of tribosystem shell/bolt/slice where will be performed metallographic examination and hardness measurement is shown in Figure 5.b.

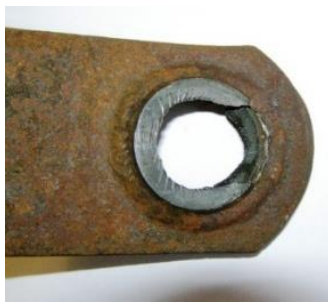

a)

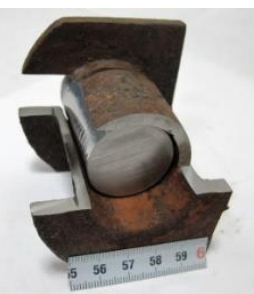

b)
Fig. 5. External slice after breaking bolt (a); the cross-section shell/bolt/slice (b).
Characteristic traces of bolt wear are shown in Figure 6.a and 6.b.

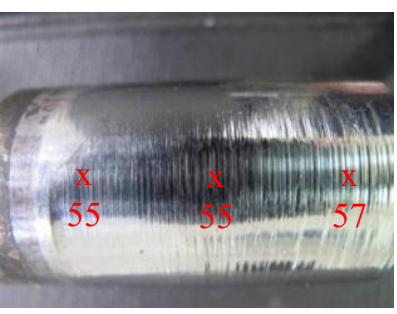

a)

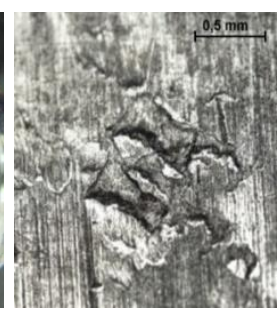

b)
Fig. 6. Characteristic wear traces of bolts, macro (a); micro (b).

Diagram in Figure 7.a shows the flow of hardness HV1 from the edge to the core of the bolts on the unexhausted part (curve a) and on worn parts (curve b). Diagram in Figure 7.b shows the flow of hardness HV1 from the edge to the core of the shell after use.

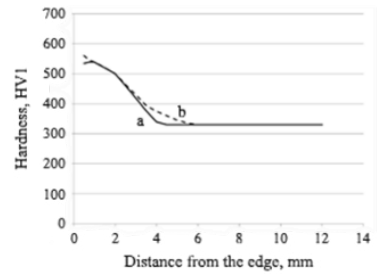

a)

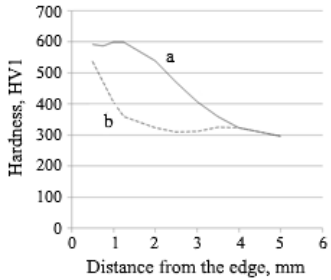

b)
Fig. 7. The flow of the hardness HV1 from the edge to the core after use of the bolts (a) and of the shell (b).

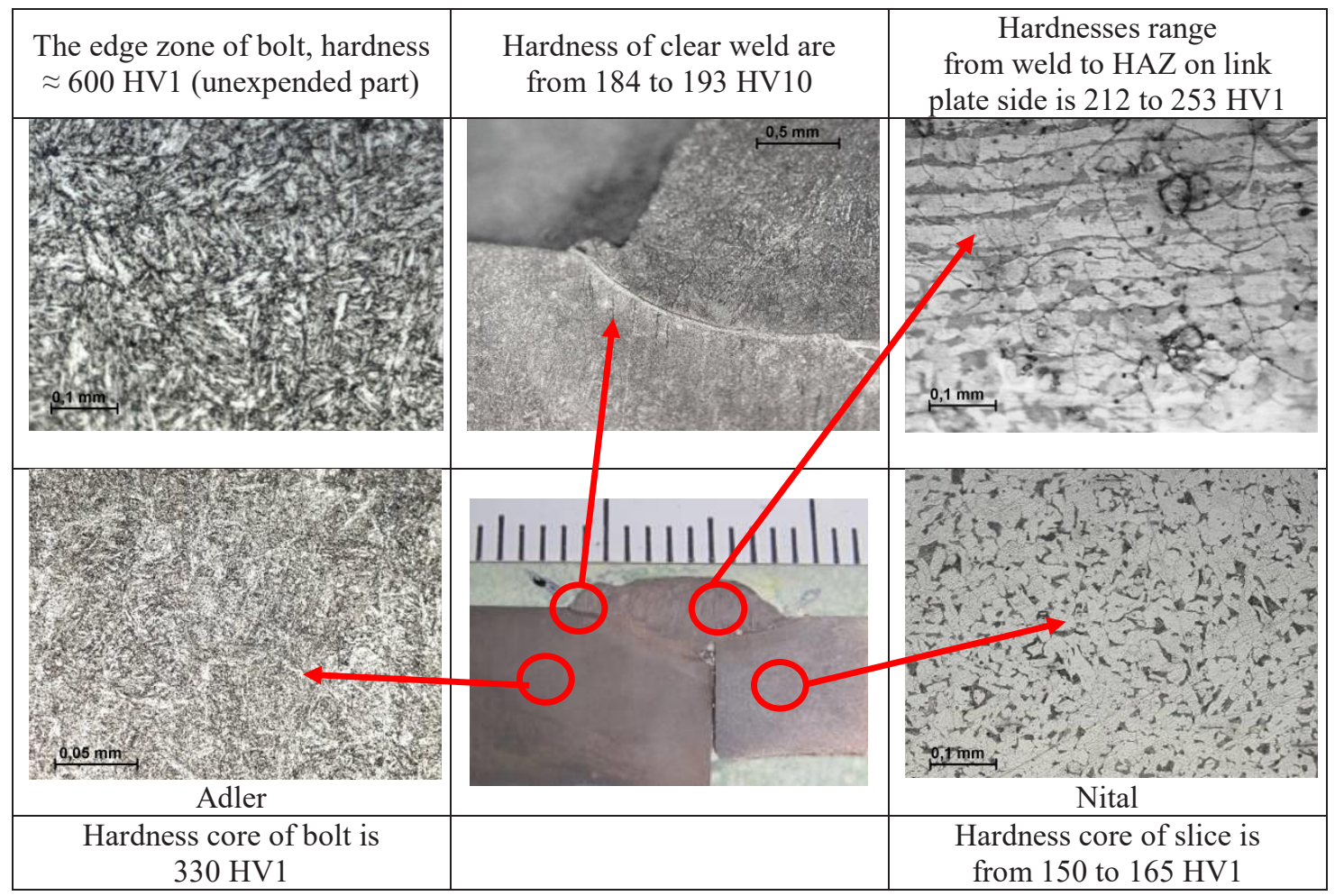

Fig. 8. Microstructure and hardness of bolt and slice.

Microstructure of bolt, slice, weld and HAZ are showed in Figure 8.
On test sample of bolts with floating benchmarks is conducted dimensional control. 
Based on measurements on ten positions, conclusion was that on the most spended part diamater is $29,7 \mathrm{~mm}$, which is the higher for $\approx 0,3 \mathrm{~mm}$ compared to the built measure of bolt. Traces of wear in the towing part of the stud characterize radial furrows caused by abrasive action of tiny particles of sunflower shell. These particles, during the work came in contact with bolt/shell, and considering the hardness of micro abrasives $\approx 6$ Mohsa [7] ,furrows“" are interrupted at the point of encountering on harder carbides are logical look of traces of wear. Figure 9 shows the cross-section of the welded joint shell/slice and values of measured hardness HV1.

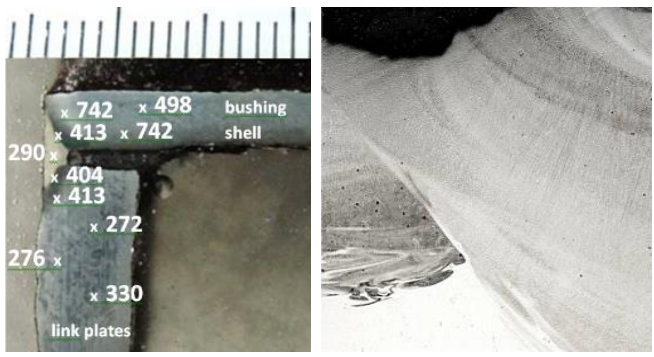

Fig. 9. Cross-section of welded compound link plate/bushing shell and values of measured hardness HV1.

Figure 10 shows results of dimensional shell control. There is a intesive wear in contact area with the bolt, wall thickness is reduced from 6 on $\approx 3 \mathrm{~mm}$.

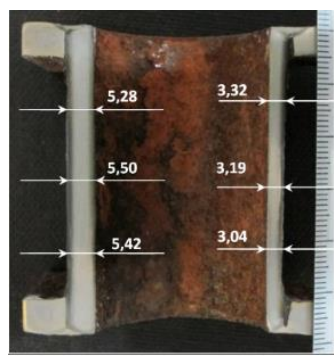

Fig. 10. Results of dimensional control of bushing shell.

Figure 11.a shows characteristic traces of wear of external surface of shell, Figure 11.b shows traces of shell wear from the inside in contact with bolt.

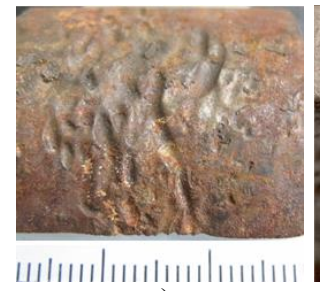

a)

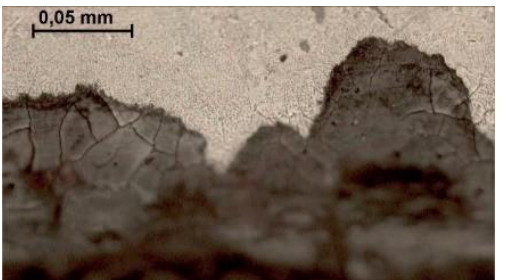

b)
Fig. 11. The typical wear traces of external carburized surface of bushing shell, the outer surface - macro (a); inner surface (b).

\section{Analyze of results and conclusion}

Based on the results of laboratory tests and comparisons of wear of original parts of chain elevator with variant bolts and shells, conclusion is: 1. the dominant wear mechanism of bolts made of martensitic corrosionresistant steel is abrasion with tiny particles of husks, same as carburized shells in contact with bolt; 2 . carburuzed shells are damaged by abrasion and corrosion due action of acid media which has $\mathrm{pH}$ value $\approx 5.2 ; 3$. wear traces of external shell carburized surface with obvious local damage, suggest that dominant mechanism is abrasion; 4. maximum measured force at break of weld joint bolt/slice is higher than the budgetary breaking force of chain. The analysis results, search of structure and the measured hardness of triboelements show that the application of this approach to solving complex problems of wear elements of straight-chain transporter can achieve significant prolongation of life. Additionally, perhaps the most important, welding shells and bolt to appropriate slice avoide the risk of fracture. this is for all structures including tribosystem most important thing, because intensity of wear based on analyze of structure, hardness, traces of wear and middle media can predict. These results make conditions for possible continuation of research which will, except to increase the wear resistance of triboelements, could go in the direction of more detailed analysis of the impact of additional material for welding shells and bolts with slices so the choice of other parameters for welding process.

\section{References}

1. K. Grilec, S. Jakovljević, G. Marić: Tribology in Mechanical Engineering, Faculty of Mechanical Engineering and Naval Architecture, Zagreb, 2015.

2. S. Perić, B. Nedić, D. Trifković, M. Varuna: An Experimental Study of the Tribological Characteristics of Engine and Gear Transmission Oils, Strojniški vestnik 59 (2013) 7-8, 443-450.

3. H. Czichos: Tribology: a systems approach to the science and technology of friction, lubrication and wear, Federal Institute for Testing Materials, Berlin, 2009.

4. V. Marušić, B. Kovačević, A. Milinović: Possibility of application of stainless steel in fabrication of parts of oil-cake chain elevator, Faculty of Technology - Institute of Field and Vegetable Crops, Novi Sad, 2011., 115-121. 5. EN 10088-2-2005: Stainless steels. Technical delivery conditions for sheet/plate and strip of corrosion resisting steels for general purposes.

6. BS EN 1600-1997: Welding consumables. Covered electrodes for manual metal arc welding of stainless and heat resisting steels. Classification.

7. B. Nedić, Ž. Rosandić, D. Jovanović, M. Čupović, V. Marušić: Influence of Tribological Processes of the Mechanisms of Free Motion on Operational Characteristic of the Impulsive Friction Variators, Strojarstvo 54 (2012) 1, 49-58. 